\title{
A Probit Regression model approach for Predicting Drought Probabilities in Zimbabwe using the Southern Oscillation Index
}

\author{
Retius Chifurira \\ School of Mathematics, Statistics and Computer Sciences, University of KwaZulu - Natal, \\ Private Bag X54001 Durban 4000, South Africa. \\ Email: chifurira@gmail.com \\ Delson Chikobvu \\ Department of Mathematical Statistics and Actuarial Sciences, University of Free State, \\ P.O. Box 339 Bloemfontein 9300, South Africa. \\ Email: chikobvu@ufs.ac.za
}

\section{Doi:10.5901/mjss.2014.v5n20p656}

\section{Abstract}

This paper focuses on the methodology of determining probabilities of meteorological droughts in Zimbabwe. The Probit regression method is used. Mean annual rainfall for the years 1974 to 2009 is used in this study. The results show that a very low value of the Southern Oscillation Index (SOI) for September precedes the occurrence of a meteorological drought in Zimbabwe by at least a year. Mean annual rainfall drought threshold value of $570 \mathrm{~mm}$ is used to categorize drought years from 1974 to 2009. Results show that a negative Southern Oscillation Index value for September predicts at least $67 \%$ chance of drought in the coming year.

Keywords: Mean annual rainfall, Probit regression, Southern Oscillation Index, Drought Probabilities.

\section{Introduction}

Zimbabwe has been ravaged by erratic rainfall patterns and sometimes leading to droughts. During 1991 to 1992 rainfall season, Zimbabwe and some Southern African Development Community (SADC) countries experienced the worst drought in living memory (Zimbabwe Central Statistical Report, 1994). Drought implies scarcity of water, which adversely affects various sectors of human society e.g. agriculture, hydropower generation, water supply and industry (Panu and Sharma, 2002). In Zimbabwe, droughts occur frequently and are often severe, imparting negatively on the country's economic performance. At least 50\% of the Gross Domestic Product (GDP) in Zimbabwe is derived from rain-fed agriculture (Jury, 1996). Thus, apart from immediate food shortages, droughts have a significant impact on the overall performance of the agriculturally based economy. Good timely predictions will assist farmers with planning for each rainfall season, for instance; using drought resistant crops or varieties given the expected drought probability. It is then imperative that a simple tool be advanced to predict the probability of drought as early as at least a year in advance and as accurately as possible.

The prime cause of drought is the occurrence of below normal precipitation, which is affected by various natural phenomena. As noted by Panu and Sharma (2002), most notable large scale climatic variation that occurs from one year to another is the Southern Oscillation climatic condition, which manifests itself in the differential oceanic temperature phenomenon across the tropical Pacific Ocean. This paper aims to determine drought probabilities in advance using the Southern Oscillation Index (SOI), a climatic determinant.

The identification and prediction of droughts are achieved through analysis of time series of drought variables such as rainfall, stream flow, groundwater levels, and soil moisture data on a variety of time scales (Panu and Sharma, 2002). Available researches on drought prediction in Zimbabwe focused on predicting annual rainfall. Significant differences in rainfall amount, temporal and spatial distribution have been found to occur in the country between opposite extremes in the phases of the ENSO (Matarira, 1990). Research done on the predictability of drought for Zimbabwe focussed on correlations between phases of SOI and rainfall (Matarira and Unganai, 1994; Torrance, 1990; Waylen and Henworth, 1995; Richard et al, 2000). Manatsa et al (2007) used correlation analysis to identify the period lags for which SOI and 
Darwin pressure anomalies are significantly correlated with the Zimbabwean Summer Precipitation Index. The authors found that progressive lagged four months averaged Darwin pressure anomalies are correlated with the Zimbabwean Summer Precipitation Index. Ismail (1986) proposed an Empirical Rule from which the mean seasonal rainfall over Zimbabwe can be predicted three months before the start of the rainy season and ten months before its end using Southern Oscillation. The author concluded that the Southern Oscillation Indexhas an influence on the seasonal rainfall over Zimbabwe. Chikobvu and Chifurira (2012) investigated the influence of Southern Oscillation Index (SOI) on the mean annual rainfall for Zimbabwe, the study showed that mean annual rainfall for the country can be predicted using the SOI value for September of the previous year.

Prior to the 1982 to 1984 drought period, which caused widespread environmental impact in Zimbabwe, prediction of drought was not taken seriously (Jury, 1996). With severe droughts recurring in 1992 and 1997, it has become mandatory to predict droughts. Drought and its impacts can be mitigated through the provision of reliable drought predictions with adequate lead-times (Manatsa et al, 2007). Most studies on predicting drought and rainfall in Zimbabwe have focused on correlations analysis between rainfall and $\mathrm{SOI}$ values. The aim of this paper is to model the drought probabilities in Zimbabwe incorporating the effect of the SOI. The study therefore departs from previous research by attempting to model the probability of drought in Zimbabwe by incorporating the effect of the SOI using the probit regression method.

\subsection{Definitions of Drought}

Palmer (1965) cited in Panu and Sharma (2002), wrote that "drought means various things to various people depending on their specific interest. To the farmer, drought means a shortage of moisture in the root zone of his crops. To the hydrologist, it suggests below average water levels in the streams, lakes, reservoirs, and the like. To the economist, it means a water shortage which affects the established economy". Thus, there are many definitions of drought; the Zimbabwe Department of Meteorological Services classifies droughts into meteorological, agricultural and hydrological as advanced by Wilhite and Glantz (1985). Meteorological drought is deemed to have occurred when precipitation is below the range of values (threshold) considered as normal (World Meteorological Organization, 2006). The Zimbabwe Department of Meteorological Services uses a threshold of $75 \%$ of normal average annual precipitation. The averages precipitation claims range from 663mm per year (Zimbabwe Department of Meteorological Services) to $867 \mathrm{~mm}$ per year (htttp://www.climatetemp.info/zimbabwe/). This gives a range average of approximately $760 \mathrm{~mm}$ per year. A definition of hydrological drought resolves around the effects of dry spells on surface and subsurface waters. Agricultural drought is considered to have set in, when the soil moisture availability to plants has dropped to such a level that it adversely affects agricultural production (Panu and Sharma, 2002). Thus, agricultural and hydrological drought place greater emphasis on the human or social aspects of drought. Agricultural and hydrological drought highlights the interaction or interplay between the natural characteristic of meteorological and human activities that depend on precipitation to provide adequate water supplies to meet societal and environmental demands. This paper tries to predict (at least a year in advance) the probability of a meteorological drought using the Southern Oscillation Index.

\subsection{Southern Oscillation}

The Southern Oscillation Index gives a simple measure of the strength and phase of the difference in sea level air pressure of the area between Tahiti (in the Mid Pacific) and Darwin (in Australia). A strong and consistent negative SOI pattern is related to ElNiño. Conversely, a deep and consistent positive SOI pattern is related to LaNiña. ElNiño (associated with negative SOI phases) is usually associated with below normal rainfall and LaNiña (associated with positive SOI phases) is associated with above normal rainfall. ElNiño is the abnormal warming in temperature of surface ocean waters in the eastern tropical Pacific Ocean. While, LaNiña is the cooling of surface ocean waters in the eastern tropical Pacific Ocean. If ElNiño takes place in the eastern tropical Pacific Ocean (Northern Hemisphere), LaNiña will simultaneously take place in the western tropical Pacific Ocean. The changes in temperature of the ocean waters affect surface air pressure in the Pacific Ocean, a phenomenon known as Southern Oscillation. Southern Oscillation is the seesaw pattern of reversing surface air pressure between the eastern and western tropical Pacific Ocean: when the surface pressure is high in the eastern tropical Pacific Ocean, it is low in the western tropical Pacific Ocean and vice versa.

This research uses monthly SOI values to predict meteorological drought probabilities. 


\section{The Data}

In this section data sources are discussed.

\subsection{Drought years}

The rain season in Zimbabwe begins from October. This paper uses annual rainfall data obtained from the Department of Meteorological Services i.e October to September and a drought threshold value of $75 \%$ of average annual rainfall of 760 $\mathrm{mm}$. The drought years from 1974 to 2009 are determined using the formula:

Drought year if: Mean annual rainfall $<0.75 \times$ average expected annual rainfall.

The average expected annual rainfall is taken as the average rainfall from 1980 to 2010 and is $760 \mathrm{~mm}$. Any mean annual rainfall less than $75 \%$ of $760 \mathrm{~mm}$ is regarded as a drought year. The Department of Metereological Services uses a 30-year time series obtained from aerially averaging ten rainfall stations with long enough rainfall data sets. The stations are located across the country and from all five agricultural regions of the country.

\subsection{Southern Oscillation Index}

The SOI data is obtained from the Internet $h t t p: / / w w w . l o n g p a d d o c k . q l d . g o v . a u$. The SOI is calculated from the monthly or seasonal fluctuations in the air pressure difference of the area between Tahiti (in the mid-Pacific) and Darwin (in Australia). The SOI gives a simple measure of the strength and phase of the difference in sea-level pressure between Tahiti and Darwin. The difference is given in terms of an index. A strong negative value usually indicates that the oscillation has entered a ElNiño phase. A strong positive value usually indicates a LaNiñaphase. The SOI usually ranges from about -35 to about +35 , and the value of the $\mathrm{SOI}$ can be quoted as a whole number.

\section{Methodology}

To predict the probability of drought in a given year, the year can be declared a meteorological drought if annual rainfall is less than 75 percent of the normal rainfall. Presence or absence of drought can be viewed as a Bernoulli trial, where success is the presence of drought and failure is the absence of drought. Thus, a year is either classified as a drought or not a drought year. Rainfall data will be categorized into drought year and non-drought year. Mean rainfall amount less than $570 \mathrm{~mm}$ will be categorized as a drought, indexed 1, and mean rainfall more than $570 \mathrm{~mm}$ as no drought, indexed 0 . Thus drought index can be treated as binary data. A binary response variable arises by classification as success (drought) when a quantitative test observation falls outside specifications limits $(<570 \mathrm{~mm})$. The binary response random variable is defined as:

$$
D_{t}=\left\{\begin{array}{c}
1 \text { if the mean annual rainfall is less than } 570 \mathrm{~mm} \\
0 \text { Otherwise }
\end{array}\right.
$$

We view $d_{t}$ as a realization of a random variable $D_{t}$ that can take the value one and zero with probabilities $\pi_{t}$ and $1-\pi_{t}$ respectively. The distribution of $D_{t}$ is called a Bernoulli distribution with parameter $\pi_{t}$ and can be written as:

$\operatorname{Pr}\left\{D_{t}=\mathrm{d}_{\mathrm{t}}\right\}=\pi_{t}^{d_{t}}\left(1-\pi_{t}\right)^{1-d_{t}}$

For $d_{t}=0,1$.

and if there are $T$ such realisation of the random variables $d_{1} \ldots \ldots \ldots d_{T}$ which are independent, with $\operatorname{Prob}\left(d_{t}=1\right)=\pi_{t}$, then their joint probability is

$\prod_{t=1}^{T} \pi_{t}^{d_{t}}\left(1-\pi_{t}\right)^{1-d_{t}}=\exp \left[\sum_{t=1}^{T} d_{t} \ln \left(\frac{\pi_{t}}{1-\pi_{t}}\right)+\sum_{t=1}^{T} \ln \left(1-\pi_{t}\right)\right]$

The expected value and variance of $D_{t}$ is

$$
E\left(D_{t}\right)=\mu_{t}=\pi_{t} \text { and } \operatorname{var}\left(D_{t}\right)=\sigma_{t}^{2}=\pi_{t}\left(1-\pi_{t}\right)
$$

The mean and variance depend on the underlying probability $\pi_{t}$. Any factor that affects the probability will alter the mean and variance of the observations. This suggests that a linear model that allows the predictors to affect the mean but assumes that the variance is constant will not be adequate for the analysis of binary data.

When all the $\pi_{t}$ 's are equal we can define:

$D=\sum_{t=0}^{T} d_{t}$

so that $D$ represents the number of successes in $T$ "trials", then the distribution of $D$ is binomial with parameters $\pi$ and $T$.

$D \sim \operatorname{Bin}(T ; \pi)$ 
The probability distribution function of $D$ is given by:

$\operatorname{Pr}(D=d)=\left(\begin{array}{l}T \\ d\end{array}\right) \pi^{d}(1-\pi)^{T-d}, d=0,1 \ldots \ldots \ldots . T$.

The expected value and variance of $D$ are $E(D)=\mu=T \pi$ and $\operatorname{var}(D)=\sigma^{2}=T \pi(1-\pi)$

\subsection{Models for binary responses}

To investigate the relationship between the response probability $\pi_{t}$ and the covariate vector $\boldsymbol{X}_{t}^{\prime}$, it is convenient to construct a formal model capable of describing the effect on $\pi_{t}$ of changes in $\boldsymbol{X}_{t}^{\prime}$.

The model embodies assumptions such as:

a) Zero correlation.

b) Lack of interaction and

c) Linearity of residuals.

Suppose therefore that the dependence of $\eta$ on $\boldsymbol{X}_{t}^{\prime}$ occurs through the linear combination $\eta=\sum_{j=0}^{p} x_{j} \beta_{j}$

for unknown coefficients $\beta_{0} \ldots \ldots \ldots \ldots \beta_{p}$ and the probabilities of observing a value of one is modelled as:

$\operatorname{Pr}\left(d_{t}=1 \mid x_{t}, \beta\right)=1-F\left(-\boldsymbol{X}_{t}^{\prime} \boldsymbol{\beta}\right)$

Where $\boldsymbol{\beta}=\left[\beta_{0}, \ldots \ldots, \beta_{p}\right]^{/}$and $\boldsymbol{X}_{t}=\left[\begin{array}{lll}1 & x_{1} \ldots \ldots \ldots \ldots x_{p}\end{array}\right]$

Where $F$ is a continuous, strictly increasing function that takes a real value and returns a value ranging from zero to one and $F$ determines the type of binary model. It follows that;

$\operatorname{Pr}\left(d_{t}=0 \mid \boldsymbol{X}_{t}^{\prime} \boldsymbol{\beta}\right)=F\left(-\boldsymbol{X}_{t}^{\prime} \boldsymbol{\beta}\right)$

The specifications of the $F$ function yields a logit regression model (logistic function), probit regression model (inverse normal function) or Extreme value model (complementary log-log function), all with a systematic part:

$g\left(\pi_{t}\right)=\eta_{t}=\sum_{j=1}^{p} x_{t j} \beta_{j} \mathrm{t}=1 \ldots \ldots \ldots . T$

This systematic part is referred to as the link function. All the link functions are continuous and increasing on $(0 ; 1)$ (Dobson,1990).

\subsection{Probit Regression Model with one independent variable and a time lag of 1 year}

The probit model is a specification model for a binary response model which employs an inverse normal function as the link function:

$g\left(\pi_{t}\right)=\eta_{t}=\Phi^{-1}\left(\pi_{t}\right)=\beta_{0}+\beta_{1} x_{t-1}$

Where $\beta_{1}=\frac{-\mu}{\sigma}$ and $\beta_{2}=\frac{1}{\sigma}$, and the link function is $\phi^{-1}$, the inverse of the cdf of the standard Normal distribution. Parameters $\beta$ are estimated by maximum likelihood estimation procedure.

The probit model assumes that the random errors in the model are independent and identically distributed with a mean of zero (Dueker, 1997), while for many time series applications this is not a plausible assumption. According to Estrella and Hardouvelis (1998), the probit model has an overlapping data problem such that the forecast errors are likely to be serially correlated. This raises the possibility that tests of significance of the variables using conventional test statistics may provide meaningless results. The problem can be corrected by a method proposed by Dueker (1997). Dueker observes that adding a lag of the dependent variable increases the validity of the assumption that error terms has a mean of zero, conditional on availability of information over timet $-k$. The new model incoporatingthe proposal by Dueker in the case of modelling drought using the probit regression would then be:

$\mathrm{E}\left(\widehat{\mathrm{D}}_{\mathrm{t}}\right)=\hat{\beta}_{0}+\hat{\beta}_{1} x_{t-\mathrm{k}_{1}}+\hat{\beta}_{2} \mathrm{E}\left(\widehat{\mathrm{D}}_{\mathrm{t}-\mathrm{k}_{2}}\right)$

Where estimates of $\beta_{0}, \beta_{1}$ and $\beta_{2}$ are the maximum likelihood estimates and $k_{i}>0$ is a desired lag for $i=1,2$.

\subsection{Binary model validation}

Deviance a log-likehood statistic will be used to test goodness of fit of the model. Akaike Information Criterion will be used in this paper to select the best model.

\subsubsection{Deviance Statistic}

Deviance statistic a log-likelihood statistic can be used to test goodness of fit of the models. The thumb rule 
is Deviance $<(T-p) . T-p$ is the degrees of freedom, where $T$ is number of observations and $p$ is the number of parameters to be estimated. Deviance which is 1.5 times the degrees of freedom is acceptable. In this paper the deviance value is used to test the goodness of fit of the models.

\subsubsection{Akaike Information Criterion}

The Akaike Information Criterion (AIC) assumes that the model errors are normally and independently distributed. AIC is computed as:

$$
A I C=-\frac{2 l}{T}+\frac{2 k}{T}
$$

where $l$ is the log-likelihood; $k$ is the number of parameters to be estimated using $T$ observations. The model with the lower AIC value is preferred and hence selected. AIC is often used in model selection for non- nested alternatives (Gujarati, 1995).

\section{Results}

The results of the probit regression are discussed below.

\subsection{The Zimbabwean Mean Annual Rainfall Patterns}

Figure 4.1shows the time series of the mean annual rainfall for Zimbabwe from 1974 to 2009. Mean annual rainfall data is calculated as the mean of October to September monthly rainfall totals. The year "1974" means mean annual rainfall for the months October 1973 to September 1974. The highest rainfall was received in 1974, while the lowest rainfall was received in 1992 (the worst drought in the given history of the country). Mean annual Rainfall less than $570 \mathrm{~mm}$ is categorized as a meteorological drought.

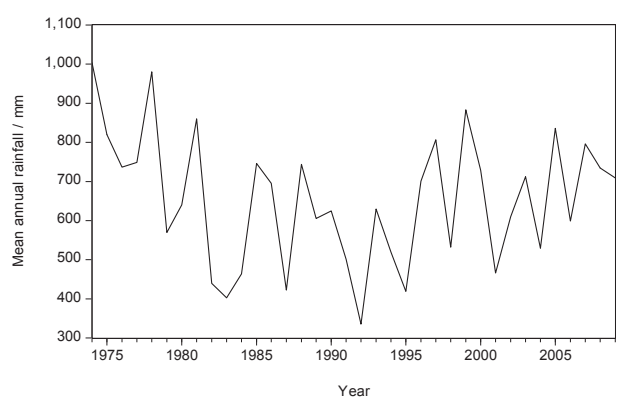

Figure 4.1 Mean annual rainfalls for Zimbabwe from 1974 to 2009

\subsection{Mean annual rainfall and Southern Oscillation Index Correlation Analysis}

The highest correlation between SOI and the Zimbabwean mean annual rainfall using the 1974 to 2009 rainfall data is +0.45 using the current April and January SOI values. The lowest correlation of +0.23 is obtained between mean annual rainfall with the February SOI value. September SOI value has a +0.33 correlation with the mean annual rainfall. However, the focus of this study is to determine a particular month's SOI which has a high correlation with mean annual rainfall at a lead time of a year or more. This is a clear departure from other researches. Considering a lag of one year, the highest correlation $(+0.36)$ between the $\mathrm{SOI}$ and the Zimbabwean mean annual rainfall is with $\mathrm{SOI}$ for September. At a lag of more than a year the correlations between the SOI and annual rainfall are insignificant.

Figure 4.2 shows the time series of SOI for September from 1974 and 2009. 


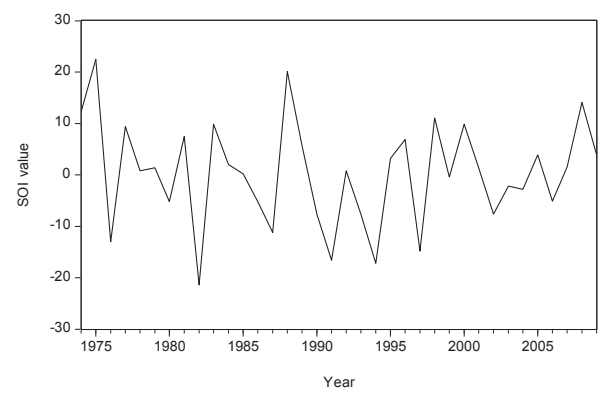

Figure 4.2 Southern Oscillation Index for September from 1974 to 2009

\subsection{Probit Regression Models}

The binary drought data is modelled using the probit regression. SOI value for September of the previous year is used as an explanatory variable. Mean annual rainfall below $570 \mathrm{~mm}$ is categorized as a drought, indexed 1, and rainfall above $570 \mathrm{~mm}$ indexed 0.

Table 4.1 shows the probit regression models using the $570 \mathrm{~mm}$ threshold and SOI value for September of the previous year.

Table 4.1 Probit Regression Models

\begin{tabular}{|c|c|c|c|c|c|}
\hline Variable & Coefficient & p value & Deviance & D F & AIC \\
\hline \multirow{2}{*}{ SOI $_{\text {sept }(-1)}$} & $\hat{\beta}_{0}=-0.446515$ & 0.0554 & 39.21368 & 33 & \multirow{2}{*}{1.234} \\
\hline SOI & $\hat{\beta}_{1}=-0.056530$ & 0.0251 & & & \\
\hline
\end{tabular}

From table 4.1 all the deviances are less than 1.5 times degrees of freedom. Thus, all the models fit the data well. The best model to be selected is the model with the least deviance and AIC. The model is the simple probit model:

$$
\mathrm{E}\left(\widehat{\mathrm{D}}_{\mathrm{t}}\right)=\hat{\beta}_{0}+\hat{\beta}_{1} x_{t-\mathrm{k}_{1}}
$$

with a probit link function, where $D_{t}=\Phi^{-1}\left(\pi_{t}\right)$ is the probability of drought occurring and $x_{t-1}$ is the SOI value for September of the previous year. The estimate of the parameter

$\beta_{0}$ is -0.446515 ( $p$ value $\left.=0.0554\right)$ and $\beta_{1}$ is -0.056530 ( $p$ value $=0.0251$ ). If the SOI value for September of the previous year is negative, the model predicts a drought. If the SOI value for September of the previous year is positive, the model predicts no drought. The simple probit model, as pointed out by Dueker (1997), has one deficiency of assuming that the error terms are independent and identically distributed with a mean of zero.

Table 4.2 shows the modified probit regression model proposed by Dueker (1997) which corrects for serial correlation of residuals in the simple probit model.

Table 4.2 Modified Probit Regression Models

\begin{tabular}{|c|c|c|c|c|c|}
\hline Variable & Coefficient & p value & Deviance & D F & AIC \\
\hline$S O I_{\text {sept }(-1)}$ & $\hat{\beta}_{1}=-0.102287$ & 0.0180 & 40.13624 & \multirow{2}{*}{33} & \multirow{2}{*}{1.261} \\
$D_{t-1}$ & $\hat{\beta}_{2}=-1.177757$ & 0.1086 & & & \\
\hline$S O I_{\text {sept }(-1)}$ & $\hat{\beta}_{1}=-0.076806$ & 0.0743 & 37.49903 & \multirow{2}{*}{33} & \multirow{2}{*}{1.221} \\
$D_{t-2}$ & $\hat{\beta}_{2}=-1.542182$ & 0.0503 & \\
\hline
\end{tabular}

From table 4.2 the best modified probit model which fits the data well is the model with the least deviance and AIC. The modified probit model is:

$$
\mathrm{E}\left(\widehat{\mathrm{D}}_{\mathrm{t}}\right)=\hat{\beta}_{0}+\hat{\beta}_{1} x_{t-\mathrm{k}_{1}}+\hat{\beta}_{2} \mathrm{E}\left(\widehat{\mathrm{D}}_{\mathrm{t}-\mathrm{k}_{2}}\right)
$$

The model is significant with the estimated parameters $\beta_{0}$ is -0.076806 ( $p$ value $=0.0743$ ) and $\beta_{1}$ is -1.542182 ( $p$ value $=0.0503$ ). It is important to check if the simple probit model has good forecasting power. 


\subsection{Checking model forecasting power}

Figure 4.3 shows the graph of drought versus predicted meteorological drought probability using the simple probit model, indicating that the model can be used to predict drought in Zimbabwe. The grey colours show years of meteorological drought.

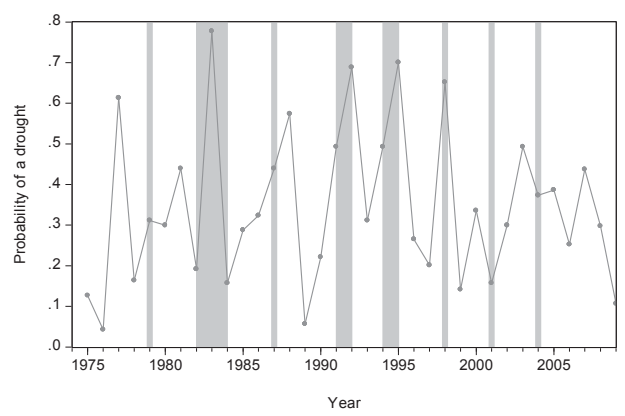

Figure 4.3 Predicted Drought Probability using simple Probit model

The modified model proposed by Dueker (1997) is significant, it is important to find if itis different from the simple probit model in terms of focasting ability. Figure 4.4 shows the graph of predicted drought probability using the simple probit model versus predicted drought probability using the modified probit model.

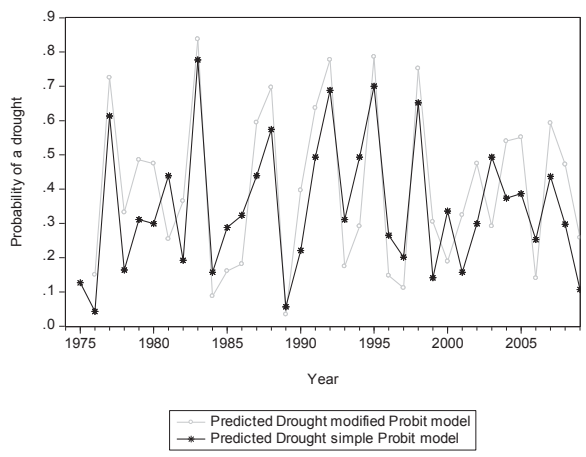

Figure 4.4 Predicted Drought probabilities using modified Probit model against simple probit model

Figure 4.4 shows that the prediction of the simple probit regression model is almost the same with prediction using the modified probit regression model.

\subsection{Forecasting drought probability}

Table 4.3 shows the predicted drought probabilities using SOI for September of the previous year.

Table: 4.3 Probability of drought as predicted by the simple Probit model

\begin{tabular}{|c|c|c|c|c|c|c|c|c|c|c|}
\hline Prob $\%$ & 10 & 20 & 30 & 32.75 & 40 & 50 & 60 & 70 & 80 & 90 \\
\hline SeptSOI $(-1)$ & 14.8 & 7.0 & 1.4 & 0.0 & -3.4 & -7.9 & -12.4 & -17.2 & -22.8 & -20.6 \\
\hline
\end{tabular}

In the Table 4.3 the SOI for September of the previous year of -7.9 , predicts $50 \%$ probability of drought. The SOI for September of the previous year of -22.8 predicts a 90 percent chance of drought, while September SOI of the previous year of more than 14.8 predicts less than $10 \%$ chance of drought. 


\section{Summary}

This paper has shown that drought probabilities for Zimbabwe can be predicted using the Southern Oscillation Index for September of the previous year. The aim of this paper was to provide a simple but reliable drought prediction model using a climatic determinant SOI value of a particular month at a maximum lag for effective planning. Mean annual rainfall is found to correlate significantly $(+0.36)$ with the SOI value for September of the previous year. Correlations at a lag of more than one year are found to be insignificant. Mean annual rainfall of $570 \mathrm{~mm}$ is used as a drought threshold. Mean annual rainfall below $570 \mathrm{~mm}$ is categorised as drought indexed 1. Mean annual rainfall above $570 \mathrm{~mm}$ is categorised as non-drought indexed 0 . It is found that a $67 \%$ chance of a drought is predicted, if the SOI value for September of the previous year is negative.

The simple model is found to be model: $\mathrm{E}\left(\widehat{\mathrm{D}}_{\mathrm{t}}\right)=-0.446515-0.056530 x_{t-1}$, where $E\left(D_{t}\right)$ is in the interval $[0 ; 1]$. Using the SOI value for September 2013 of 3.9, the model forecasts for the year 2014 is between 20\% and 30\% meteorological drought.

This paper recommends that:

a) A model for forecasting the SOI values for September be advanced. Forecasted SOI values could then be used to predict drought probabilities with a lead of more than one year.

b) The Bayesian statistics approach is applied in modelling the probability of drought using SOI value for September of the previous year. Arguably, the Bayesian approach gives more information than the classical approach.

\section{References}

Chikobvu, D., \& Chifurira, R. (2012). Predicting Zimbabwe's annual rainfall using the Southern Oscillation Index: weighted regression approach. African Statistical Journal, Volume 15 pp 87 -107.

Dobson, A. J. (1990). .An Introduction to Generalized Linear Models. Chapman and Hall: London.

Dueker, M. J. (1997). Strengthening the case for Yield Curve as a Predictor of US Recessions. Federal Reserve Bank of St Louis Economic Review 79: 41 - 51

Estrella, A., \& Hardouvelis, G.(1998). The term structures as a predictor of real economic activity. The journal of Finance 46: $555-570$.

Gujarati, D. (1995). Basic Econometrics $4^{\text {th }}$ Edition. McGraw-Hill: Boston.

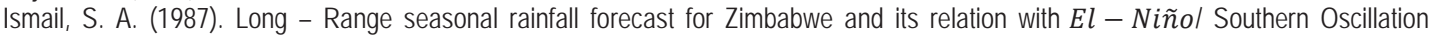
(ENSO). Theoretical and Applied Climatology Journal 38, $\quad 93-102$

Jury, M. R. (1996). Regional tele-connection pattern associated with summer rainfall over South Africa, Namibia and Zimbabwe. International Journal of Climatology.

Manatsa, D. Chingombe, W. Matsikwa, H., \& Matarira, C. H. (2007). The superior influence of the Darwin Sea Level Pressure anomalies over ENSO as a single drought predictor in Southern Africa. Theoretical and Applied Climatology D01 10.1007/s00 704 - 007 0315-3.www.springerlink.com/index/8703666K421773hpdf

Matarira, C. H. (1990). Drought over Zimbabwe in a regional and global context. International Journal of Climatology 10: 609 - 625.

Matarira, C. H., \& Unganai, L. S. (1994). A rainfall prediction scheme for southern Africa based on the southern oscillation. Technical report, SADC-REWU, Harare.

Obasi, G. O. P. (1994). WMO's role in the international decade for natural disaster reduction. Bulletin 5 of the American Meteorological Society, 75, 1655-1661, 1994.

Panu, U.S., \& Sharma, T.C. (2002). Challenges in drought research: some perspectives and future directions. Hydrological Sciences Journal 47(S).

Richard, Y. Trzaska, S. Roucou, P. \& Rouault, M. (2000). Modification of the Southern African rainfall variability / ENSO relationship since the 1960s. Climate Dynamics 16: $883-895$.

Torrance, J. D. (1990). The Southern Oscillation and the rainy season in Zimbabwe. Zimbabwe Science News, 24: 4-6.

Wilhite, D. A., \& Glantz, M. H. (1985). Understanding the drought phenomenon: the role of definitions. Environmental studies 36, 41 - 54.

World Meteorological Organization, (1986). Guidelines to the Quality Control of Surface Climatological Data. WCP - 85, WMO, AD - No. 111: 56 .

Zimbabwe Central Statistical Office handbook (October, 2004). Environmental Statistics Report. Government Printing Office: Harare.

http://www.longpaddock.qld.gov.au 